\title{
Wind Speed Prediction by Adaptive Neuro-Fuzzy Inference System and FCM Clustering
}

\author{
Young Hoon Ko \\ Hyupsung University, Department of Computer Engineering \\ tigerko@uhs.ac.kr
}

\begin{abstract}
Wind power energy is receiving attention in recent years. The properties of wind are very hard to predict because of its heavy nonlinear characteristics. This paper predicts, the wind speed by ANFIS and FCM clustering.

The data were measured in the region of islands in Jeonnam Shinan. One xear and 10 minute interval makes 52,560 samples of data but use 48,240 samples insteadfor stable operation.

For prediction of wind speed, the covariance was examined. As a result, the input domain consists of lunar date and wind direction. This input domain has so big range of wind direction and lunar date. Therefore the whole range is paxtitioned by clusters.

For experiments, two type are chosen. one is 4 clusters and the other is 6 clusters. . The error of cluster-6 is $7.5 \%$ lower than cluster-4. This means that the prediction of cluster-6 is more accurate than cluster-4.

With four Gaussian bell membership functions, ANEIS is trained over 200 epochs by clustered data. After training, ANFIS could predict the Wind speed by lunar date and wind direction. Even if heavy nonlinear system can be predicted by ANFIS and FCM clustering.

\section{Keywords: ANFIS, FCM Wind Power Clustering \\ 1. Introduction}

The energy share of the oil has continued to decline of the last 14 years, but still accounted for $32.9 \%$ of world energy consumption. The futures price of crude oil dramatically shows the history of mankind. It shows the great depression in 1929, the oil shock in 1973 and the timancial crisis in 2008. After the top price of $150 \$$ in 2008, the price is merged to 30 of production cost. Now the oil is not the only energy. There are several kinds of energy to replace the status of oil which are wind energy, solar energy, etc. These renewable energy has continued to enhance its value. The wind energy of the renewable energy has a long history. Especially the offshore wind energy is nearly $10 \%$ of world energy supply in 2015. August 16 in 2016, England approved the offshore wind power development plan of the world's largest. Its investment reaches 77 million dollars and $800 \mathrm{M}$ Watts.
\end{abstract}

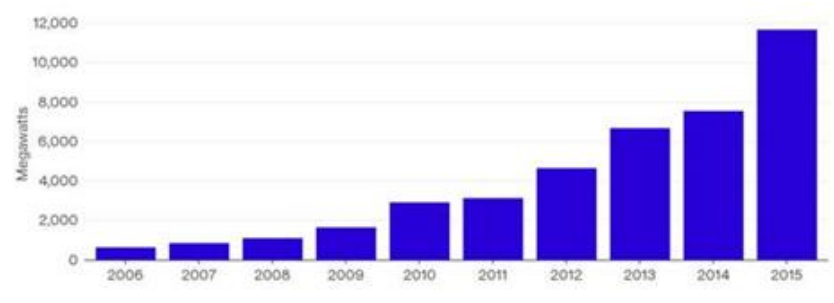

Figure 1. Offshore Wind Power by Year 
Offshore wind power as well as wind power plants is being attempted in various forms. For example, the Bahrain world trade center completed in 2009, is an energy-saving buildings that wind power is applied using strong sea breeze to cover about $10 \%$ of the whole electricity used. The major resource needed for wind power generation is the appropriate wind.

The basic properties of the wind are the wind speed and the wind direction. These properties are changed slow or fast. For the first to enable the wind power generation, the wind is needed to rotate the heavy blades. The wind condition for wind power generation should be that the average wind speed is more than $4 \mathrm{~m} / \mathrm{s}$.

Generally the wind speed at beaches is higher than other regions. So most of wind farms are located at the shore in Jeju island and the region of Jeonlanam-do Shinan-goon. And baekdudaegan also has several wind farms. Wind speed as well as wind direction is also important. It is advantageous to maintain a constant direction. In particular, wind power generation is possible only if there is a certain wind direction as the rotary axis is fixed in Bahrain world trade center. Since the maximum efficiency of power generation is achieved at vertical direction of wind, the efficiency will drop down when the wind direction is changed. Since the high specific heat of the sea, the land temperature increases in the daytime and the temperature drops at night. Depending on this characteristics, there is a sea wind in the daytime while there is an onshore yind at night.

This paper analyzes the measured data for one year from December 2012 to November 2013, were studied in an efficient way to predict the wind speed

Data were measured in the region of islands in Jeonnam Shinan. To predict the nonlinear wind speed, ANFIS is adopted which is Adaptive-Network-Based Fuzzy Inference System or Adaptive Neuro-Fu-Zy Inference System. For appropriate input domain, covariances were searched. After calculatior, the lunar date and wind direction were selected for input domain. the covariance are 72 and 135 respectively. The whole range of input domain is so huge for proper predictions, therefore input domain is partitioned by Fuzzy C-Means clustering. When data is clustered by FCM, it can be found the wind direction is partitioned. So two types are selected for comparing. One is fourdirections and the others is six-directions

Firstly clustered data by wind directions, secondly ANFIS is learned by them, and finally the wind speed is predicted by ANFIS.

ANFIS is merged by 100 epochs and then the predicted wind speed can be calculated by input donam

\section{Wind Data}

The region of islands in Jeonnam Shinan is famous for solar salt in South Korea. And it is well known as efficient wind farms. In this paper, the data were measured in the region of islands in Jeonnam Shinan for one year. The data were measured at $60 \mathrm{~m}$ altitude and 70 maltitude. The characteristic of wind is changed by altitude. So the altitude is important because it's the exact point which the wind blades are located. And one nore point can be added. It is that the amount of wind power generation is closely related to the length of the wind blade. The wind blade can be replaced by the altitude of wind turbine. The data were also measured by 10 minute interval. One year and 10 minute interval makes 52,560 samples of data.

In this paper, the Matlab is used for experiments. But the capacity of Matlab is limited by about 50,000 samples of three column matrix. To solve this problem, the modified data was used which consist of 11 months data rather than 12 months..

The next chart shows wind speed and wind direction at $60 \mathrm{~m}$ altitude. The horizontal axis is labeled with wind speed. And the vertical axis is labeled with wind direction. It can be easily seen that some range of wind direction has higher wind speed. The highest wind speed is $22.7 \mathrm{~m} / \mathrm{s}$ at $60 \mathrm{~m}$ altitude and $23 \mathrm{~m} / \mathrm{s}$ at $70 \mathrm{~m}$ altitude. In Korea, it's typically 
called typhoon when the wind speed is over than $17 \mathrm{~m} / \mathrm{s}$. So the highest wind speed must be of typhoon which happens average 2.2 times a year.

As the chart showing, higher wind speed appears in the particular directions. These directions are onshore and sea wind directions.

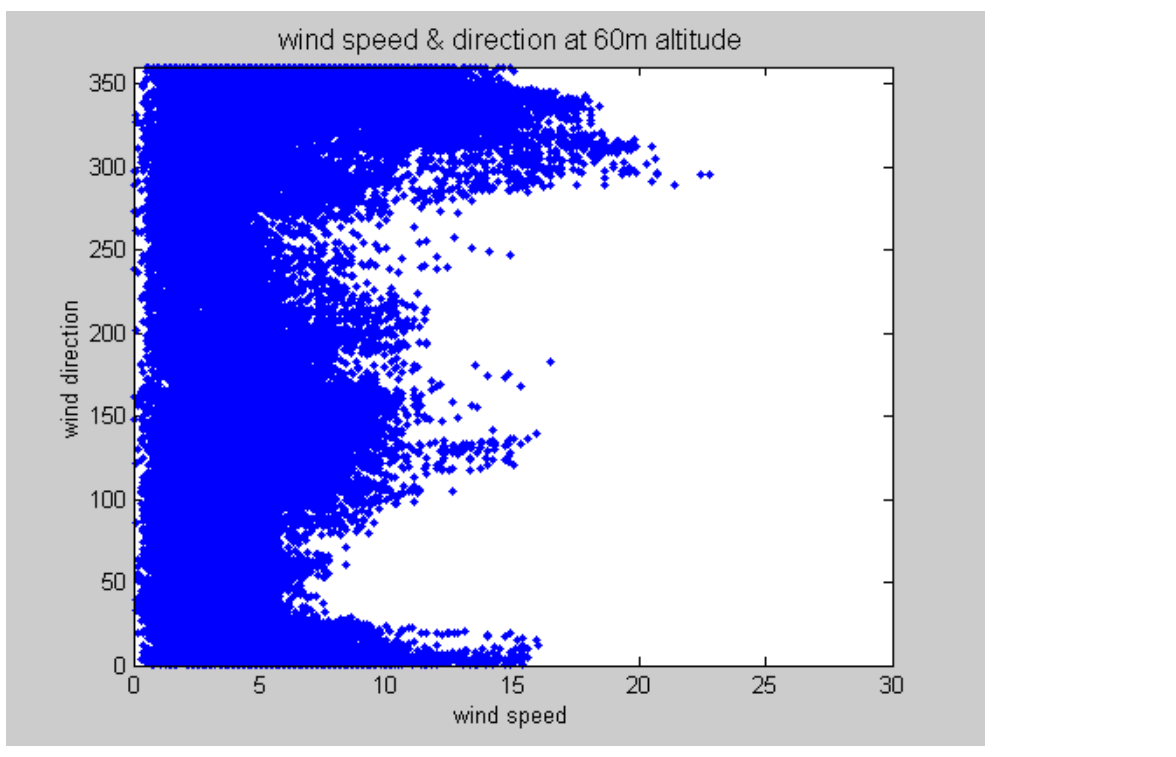

Figure 2. Measured Data by Wind Speed and Wind Direction at $60 \mathrm{~m}$ Altitude

The chart below shows wind speed and direction at $70 \mathrm{~m}$ altitude. The higher the altitude, the faster wind speed blows in general. In comparison with $60 \mathrm{~m}$ and $70 \mathrm{~m}$ altitude, they resemble the basic shape each other.

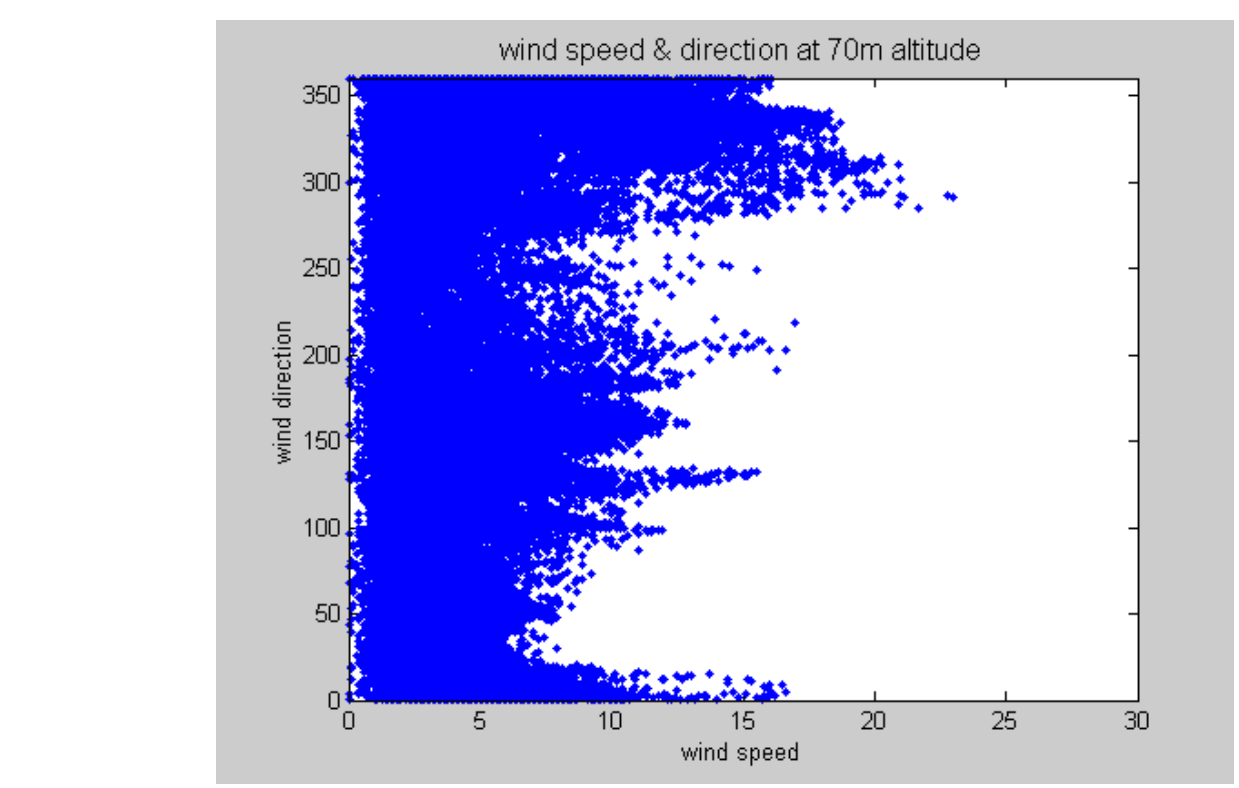

Figure 3. Measured Data by Wind Speed and Wind Direction at 70m Altitude

The figures above shows data points which are measured at instant time. But the chart below shows average wind speed at certain wind direction. The average wind speed indicates the possibility of wind power generation more clearly. The principle condition of wind power generation is that the average wind speed is over than $4 \mathrm{~m} / \mathrm{s}$. This chart 
shows most wind directions are possible for wind power generation. Especially, the direction of 150 degree get $5 \mathrm{~m} / \mathrm{s}$ of wind speed and the direction of 330 degree has over $7 \mathrm{~m} / \mathrm{s}$ of wind speed.

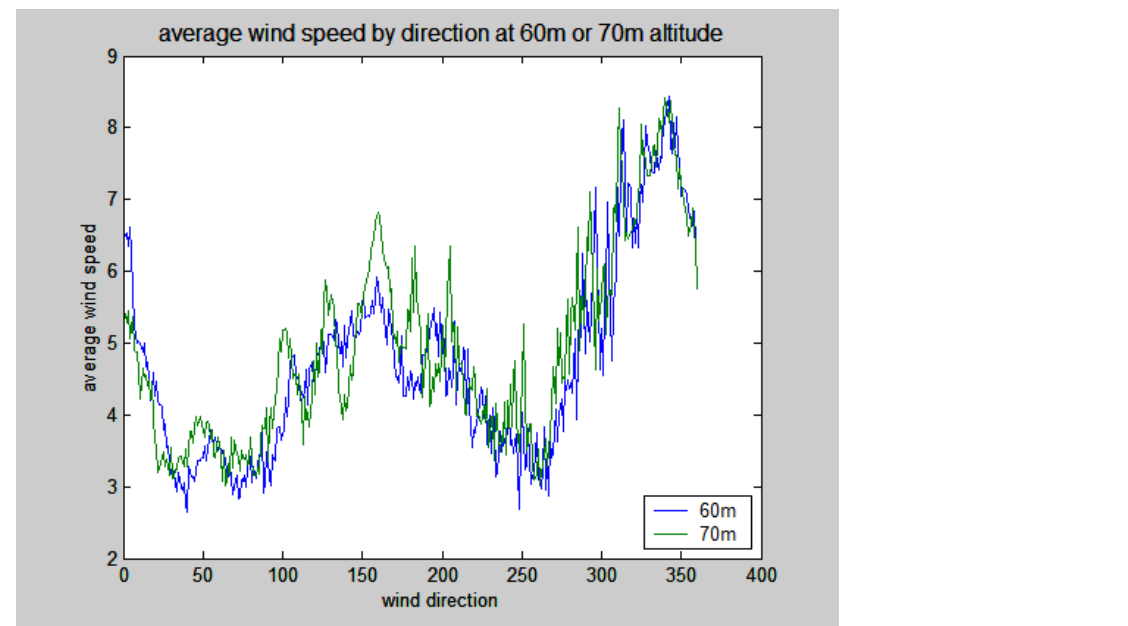

Figure 4. Average Wind Speed by Wind Direction

To predict the wind speed by other parameters, the covariances are inspected by four parameters. They are Gregorian date, lunar date, time and wind direction. 48,240 data points calculated for these covariances.

As a result, the next table includes the covariances with the wind speed. According to the table, the lunar date appears some correlation to the wind speed. The lunar date means the position of moon respect to the line from sun to earth. And wind direction also has some correlation to the wind speed $70 \mathrm{~m}$ altitude has a little bigger correlation than $60 \mathrm{~m}$ altitude. But both Gregorian date and time have no correlation to wind speed.

Tab 1 1. Covariánce between Parameters

\begin{tabular}{|l|c|c|c|c|}
\hline wind speed & Gregorian date & Lunar date & time & wind direction \\
\hline Altitude 60 m & -2 & 72 & -2 & 123 \\
\hline Altitude 70 m & -2 & 72 & -2 & 135 \\
\hline
\end{tabular}

The lunar date and wind direction is selected for input domain. And these two parameters get into AIXIS and predict the wind speed. ANFIS needs training for the first. And then it calculates the output by trained connections. Basically the input parameters and the output is nonlinear relation.

\section{FCM Clustering}

The yhole range of 360 degree is a difficult factor to get precise prediction of wind speed. To improve the correlation between inner data, the input domain should be partitioned into several clusters. There are many methods to perform clustering, this papers select FCM for clustering which is known as Fuzzy C-Means.

Using FCM, the input domain is separated by 4 clusters. The next chart shows input domain which consists of two parameters. One is lunar date of $\mathrm{x}$ axis, and the other is wind direction of y axis. After 20 epochs, the central points of FCM are merged to spread points which are the center of each cluster. Each point should belong to a certain cluster which means nearest central point of clusters. 


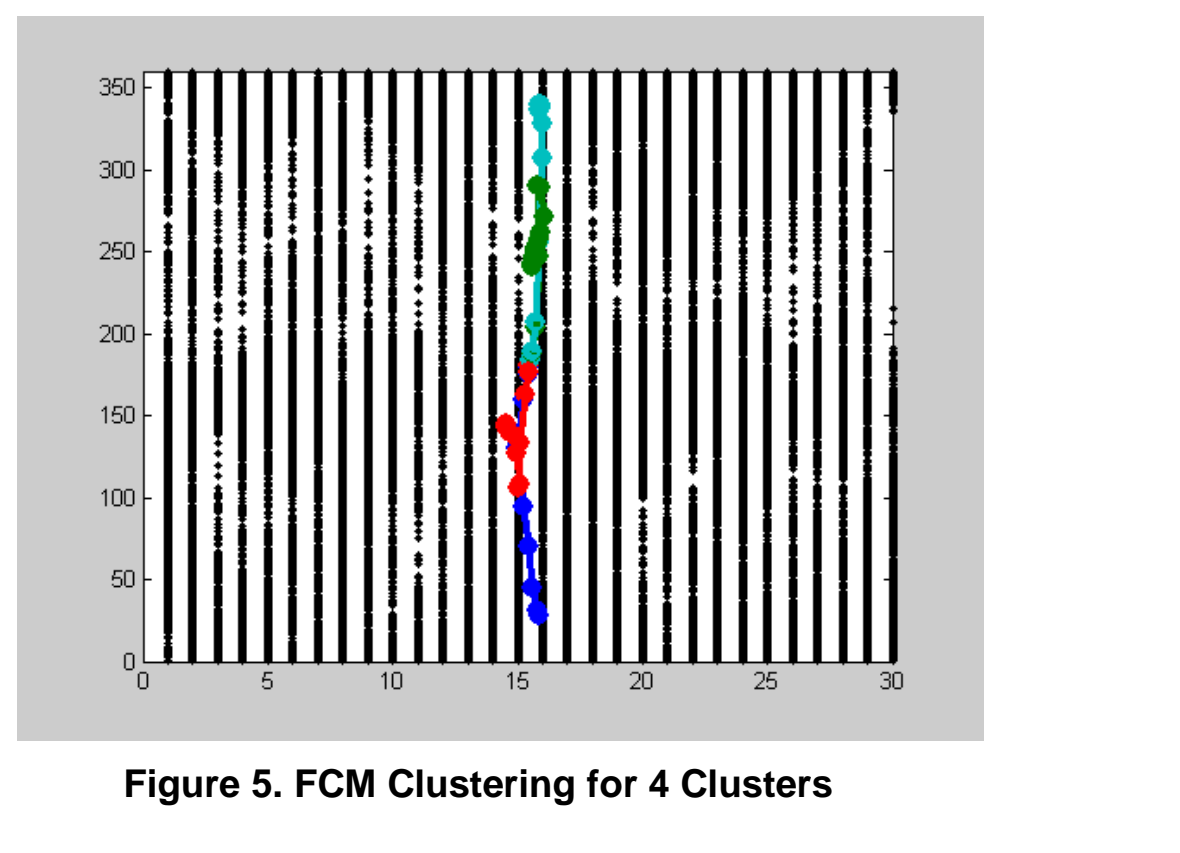

The next chart shows the colored points belong to a Cluster respectively. FCM clusters shows the cluster is separated by wind directions. For expernments, two groups are selected which has 4 clusters and 6 clusters. In four clusters, the wind directions are divided by east, north, west, south. In six clusters, the wincdirections are divided by 60 degree rotated axis.

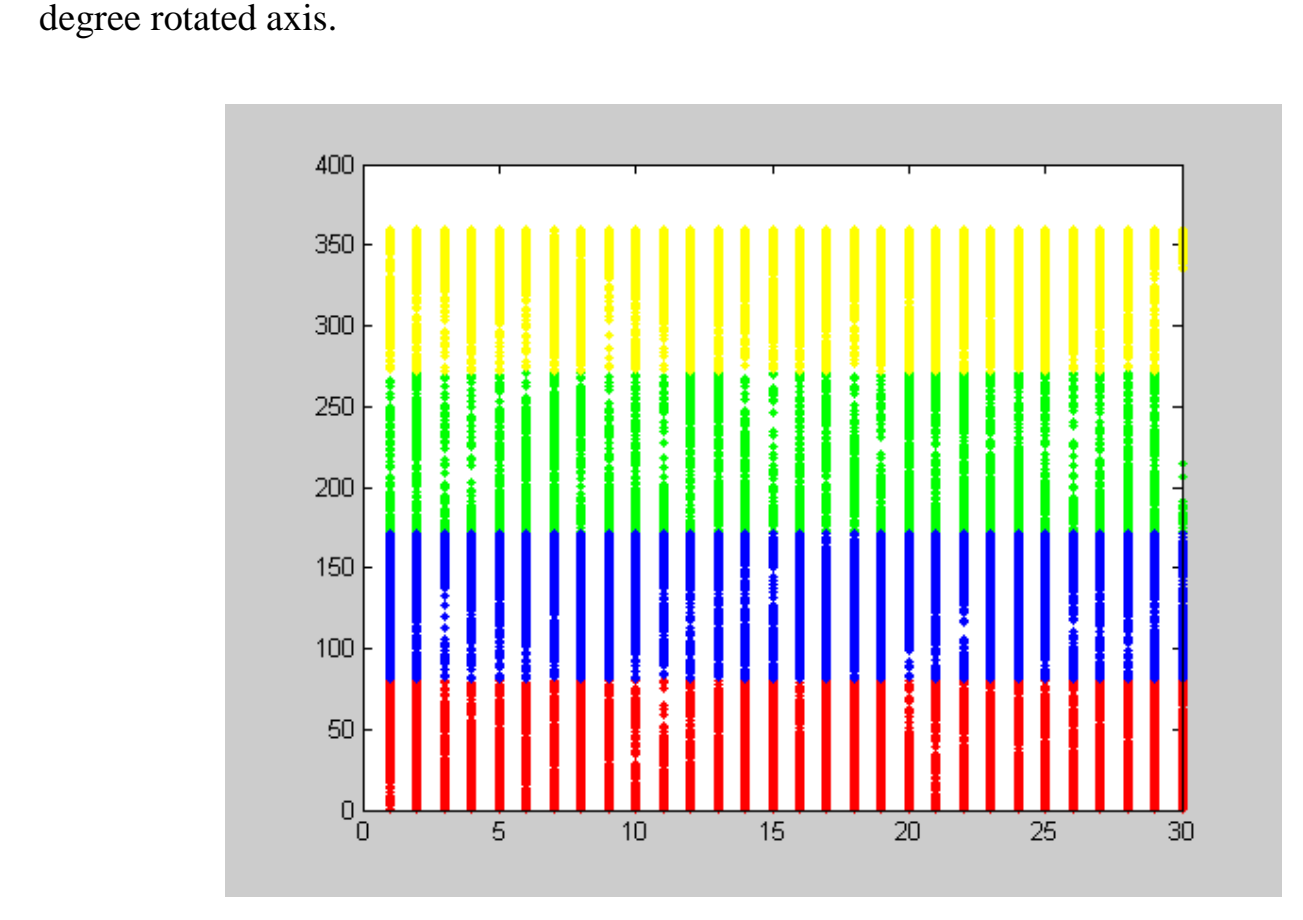

Figure 6. Colored Data Points of Clusters

If the correlations within input domain should be enhanced, the 6 clusters are more advantageous than 4 clusters. For this case, the correlation within the input domain could be enhanced, so it can be anticipated that the prediction can be improved.

The next chart shows central points merged by six clusters. These clustering are also partitioned by the wind direction. 


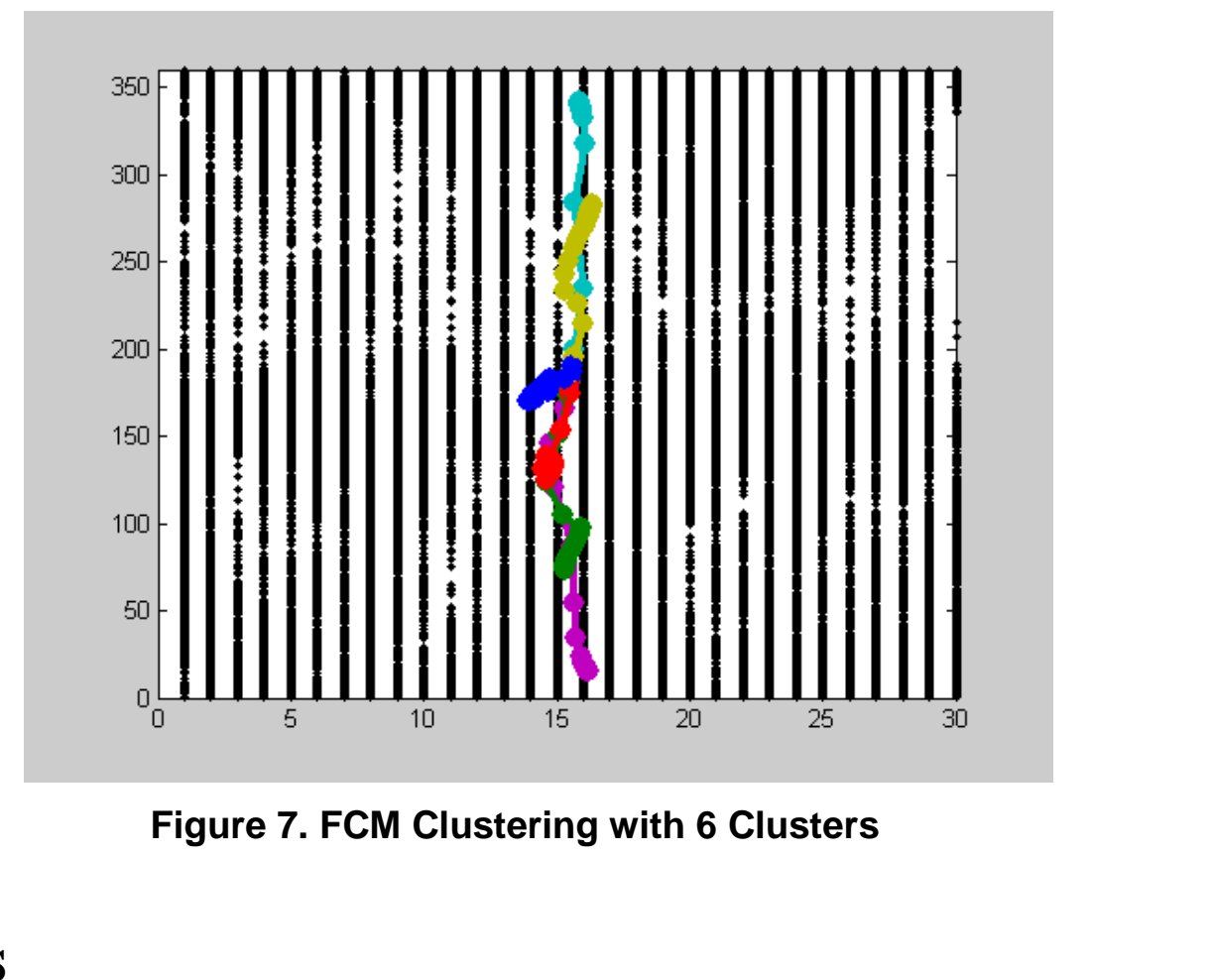

\section{ANFIS}

ANFIS is a powerful prediction tool vith training. In consists of Fuzzy inference system with Takagi-Sugeno model and Adaptive Neu@Network. ANFIS is a kind of FIS. So it has a number of membership functions and fuzzy rules. But the fuzzy rules are very simple to match just input and outpur. Generally, the ability of FIS increases if the number of membership functions increases. There are many kinds of membership functions like gaussian, trigonal, trap, etc. The gaussian bell membership function is chosen for experiments.

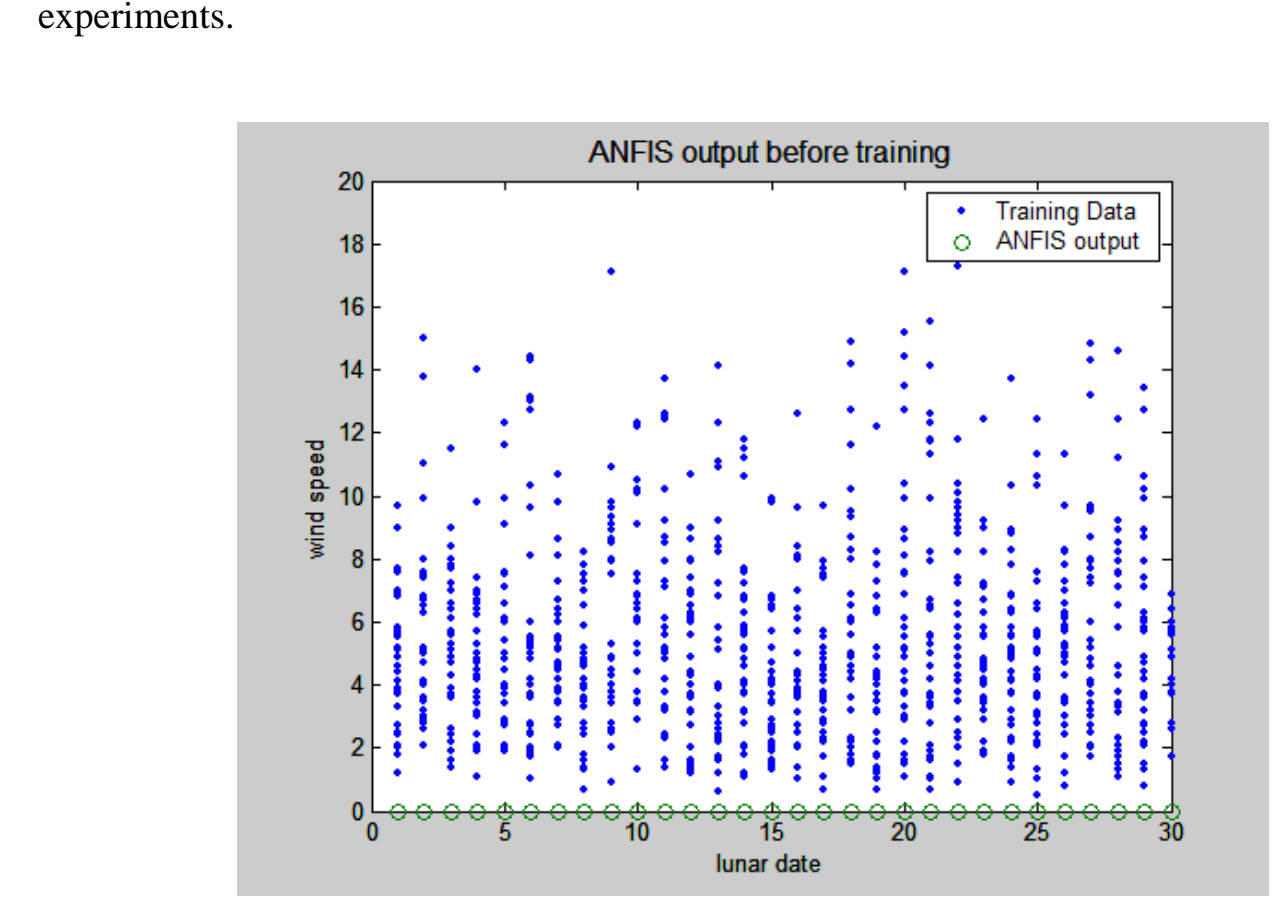

Figure 8. ANFIS Output before Training 
ANFIS includes adaptive Neural Network. So appropriate training is needed for prediction. And it also includes Fuzzy Inference System so that the membership function is also needed. This membership function should be constructed before training. For this experiments, The number of membership functions is chosen 4 and the type of membership function is gaussian bell. The figure above shows ANFIS output before training. The ANFIS output is all zero before training.

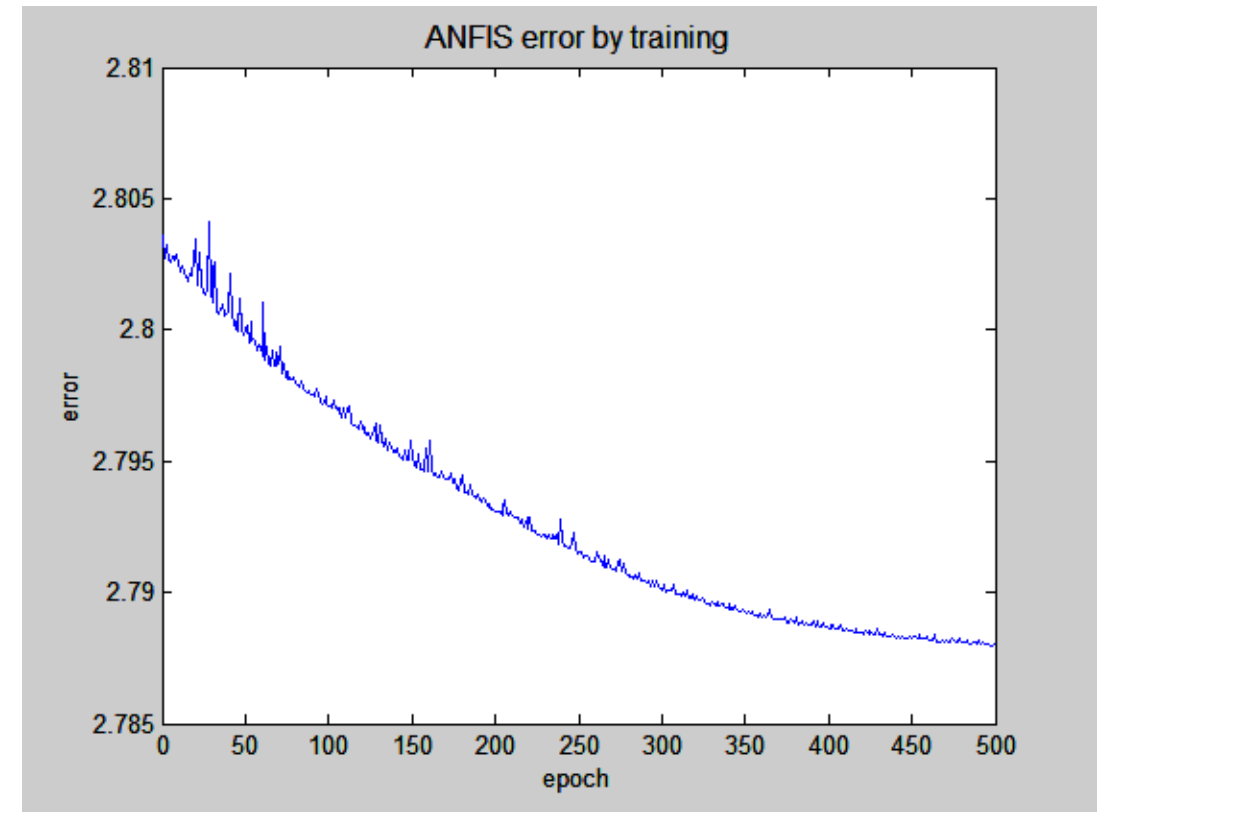

Figure 9. ANFIS Error Curve by Training

The chart above shows error curve by training. After 500 epochs, the curve is merged. After training, ANFIS ouput predicts the wind speed on the way to minimize error between training data and output. The next chart shows predictions of wind speed by lunar date which is one of the input domain.

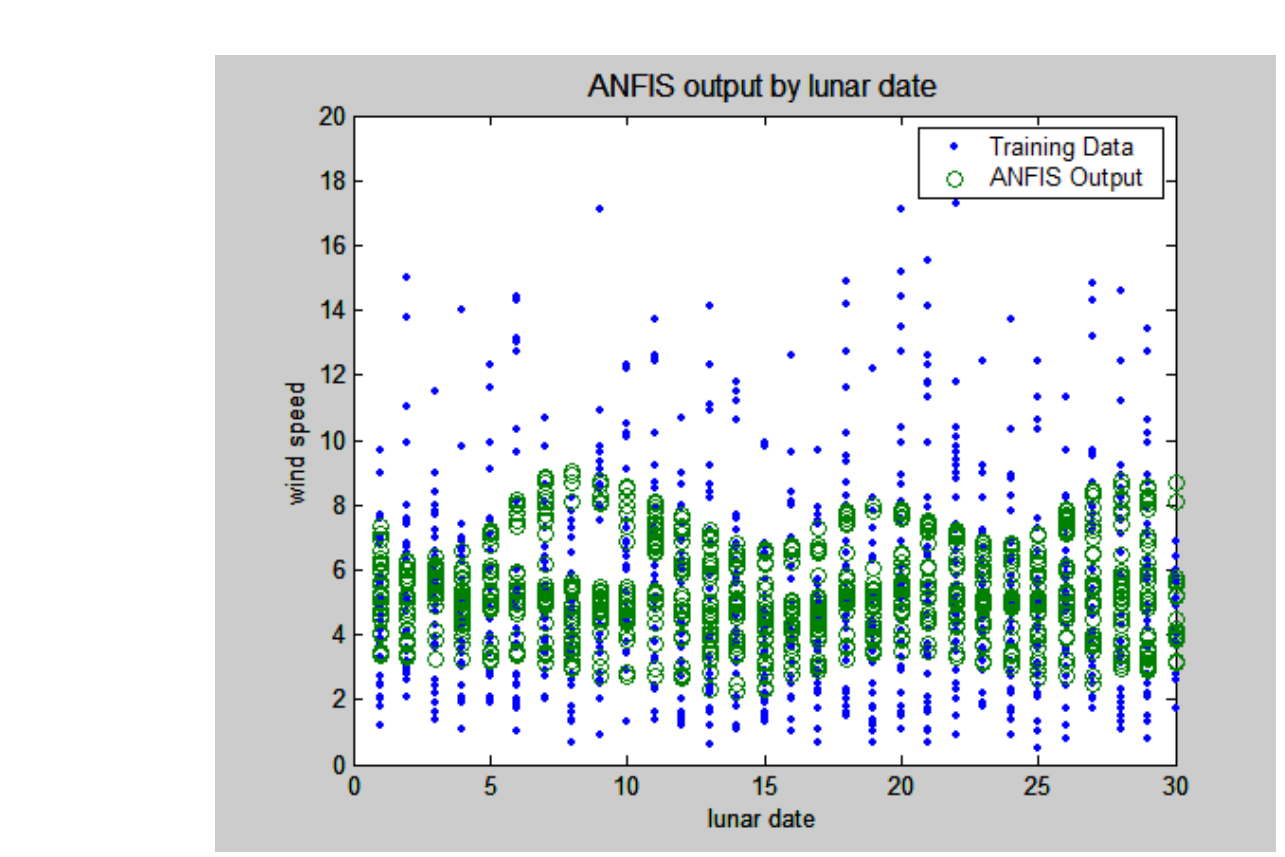

Figure 10. ANFIS Output by Lunar Date 


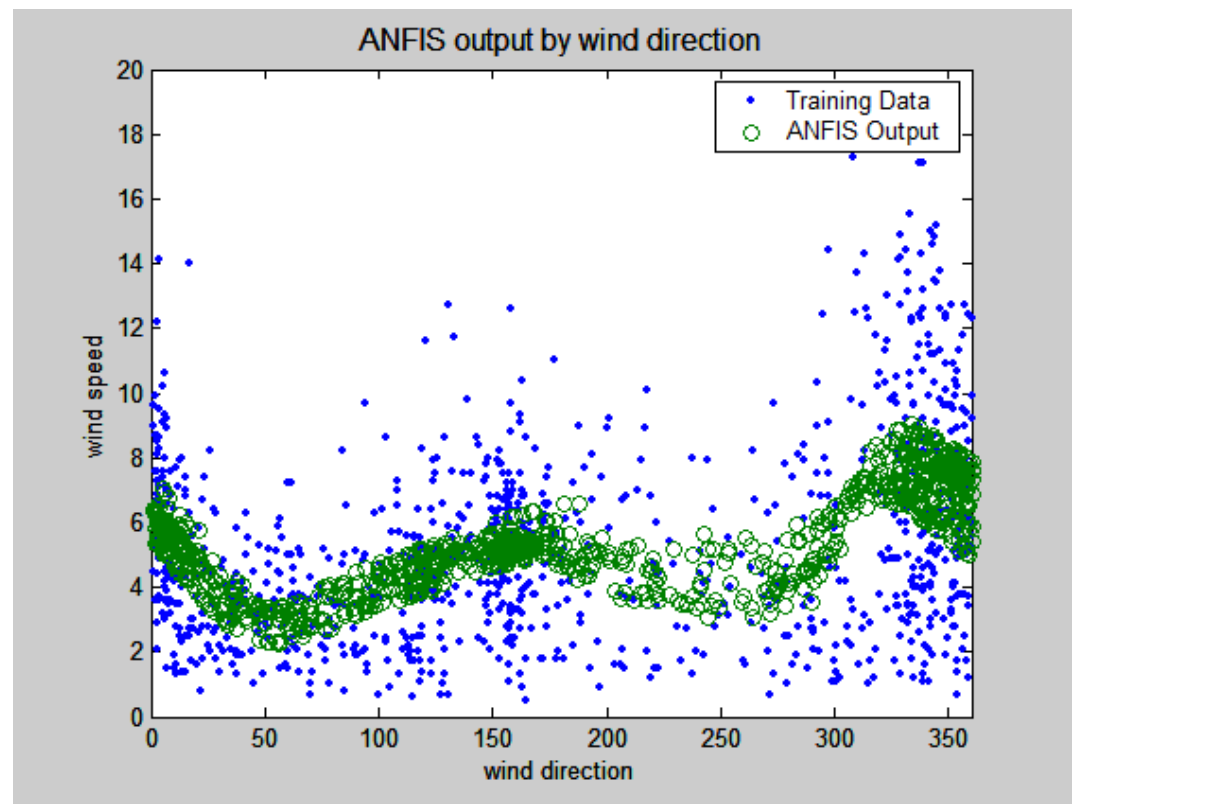

Figure 11. ANFIS Output by Winc Directiôn

Input domain consists of two parameters. They are lunar date and wind direction. The chart above shows ANFIS output by wind direction. The range of wind direction is from 0 to 360. A whole range of wind direction is not efficient because the correlations between data is small. So whole range is divided by 6 or 6 clusters. They are labeled cluster-4, cluster-6 respectively for convenience. The error of cluster-6 is $7.5 \%$ lower than cluster- 4 . This means that the prediction of cluster-6 is more accurate than cluster-4.

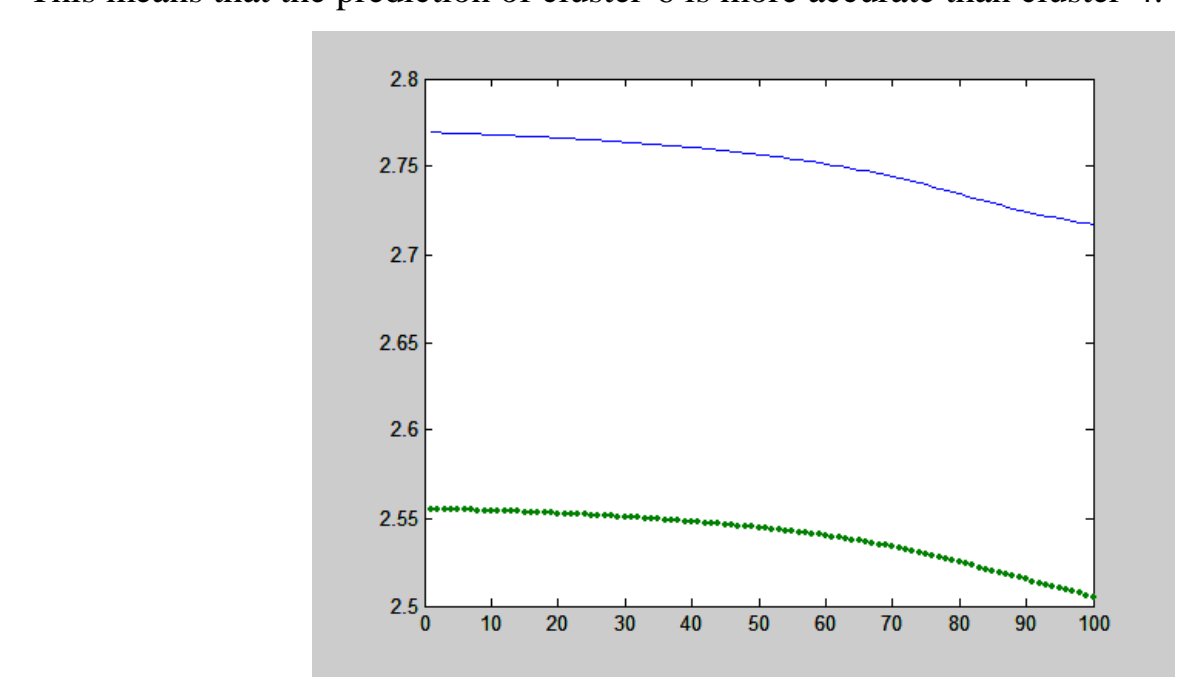

Figure 12. Errors for Cluster-4 and Cluster-6

\subsection{Cluster-4}

In 4 clusters, 4 ANFIS should be trained from clustered input domain respectively. The ANFIS initializes the membership functions for training. The number of membership functions should be chosen. Before the training, ANFIS output is just zero. According to training, the membership functions are reformed by minimizing RMSE.

Training with clustered input data, The error could be shown to be merged after 100 epochs. The chart below shows error curves of 4 clusters respectively. 

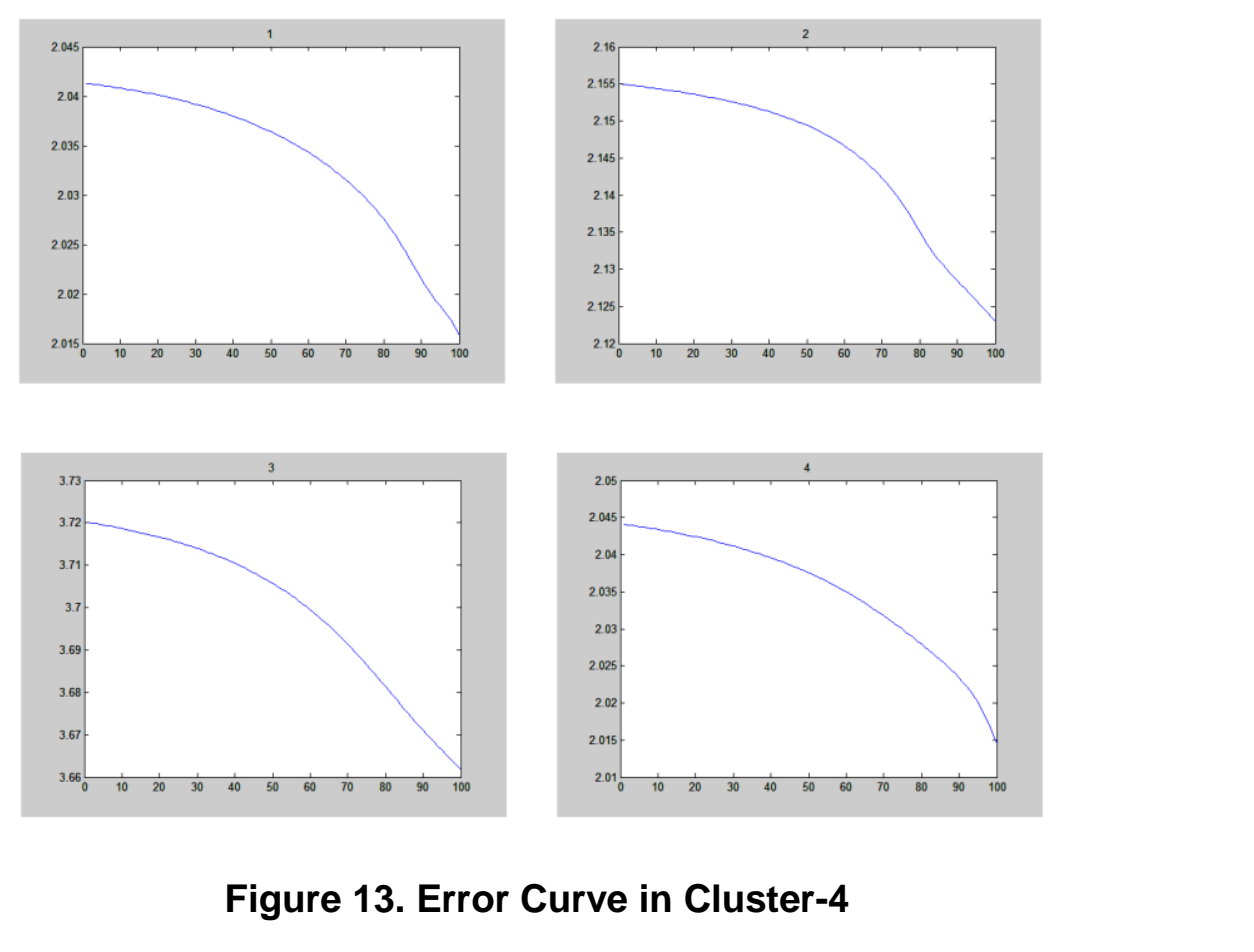

Figure 13. Error Curve in Cluster-4

After training, ANFIS output indicate the prediction of Gind speed by lunar date and wind direction. The chart below shows ANFIS output by lunąr date.

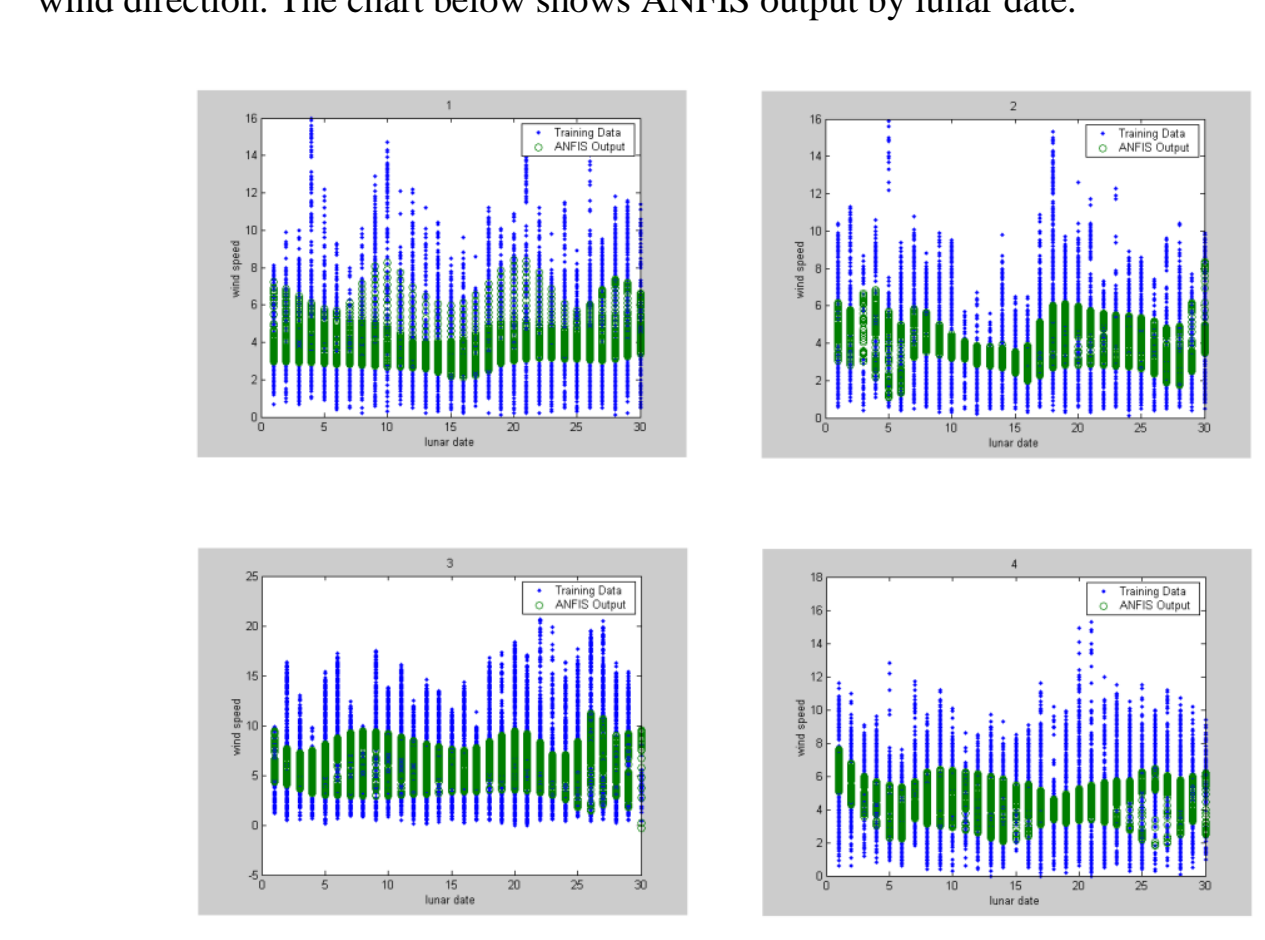

Figure 14. ANFIS Output by Lunar Date

The chart below shows ANFIS output by wind direction. If the four clusters combine, the whole range of wind direction become 360 degree. 

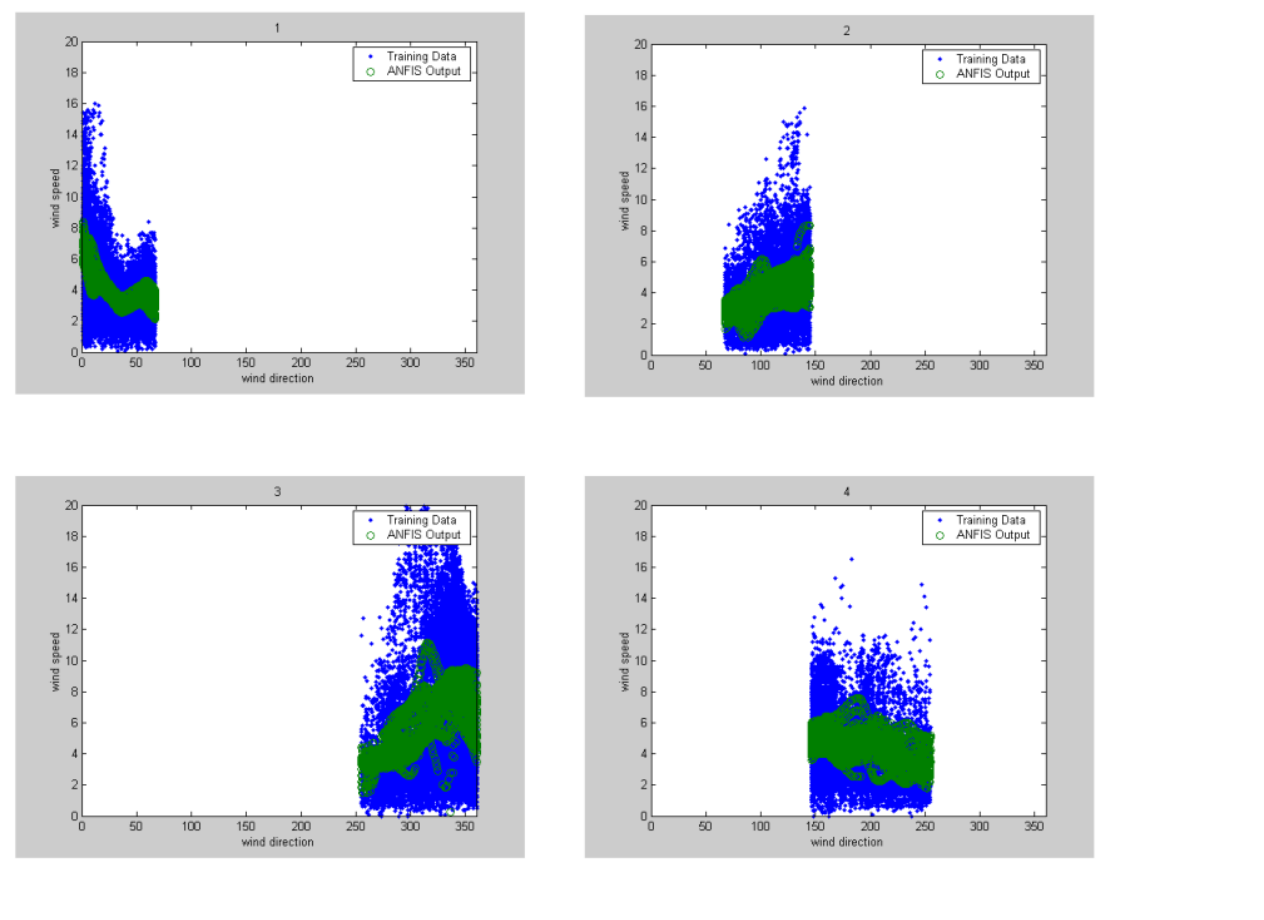

Figure 15. ANFIS Output by Wind Pirection

\subsection{Cluster-6}

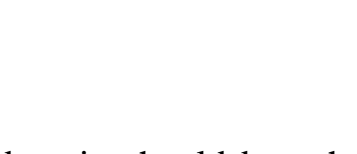

If the correlations within inpu domain should be enhanced, the 6 clusters are more advantageous than 4 clusters. For this case, the correlation within the input domain could be enhanced, so it can be anticipated that the prediction can be improved.

The next figure show assembly of ANFIS output before the training. So the ANFIS output is just zero. the data points are a little bit different by cluster.

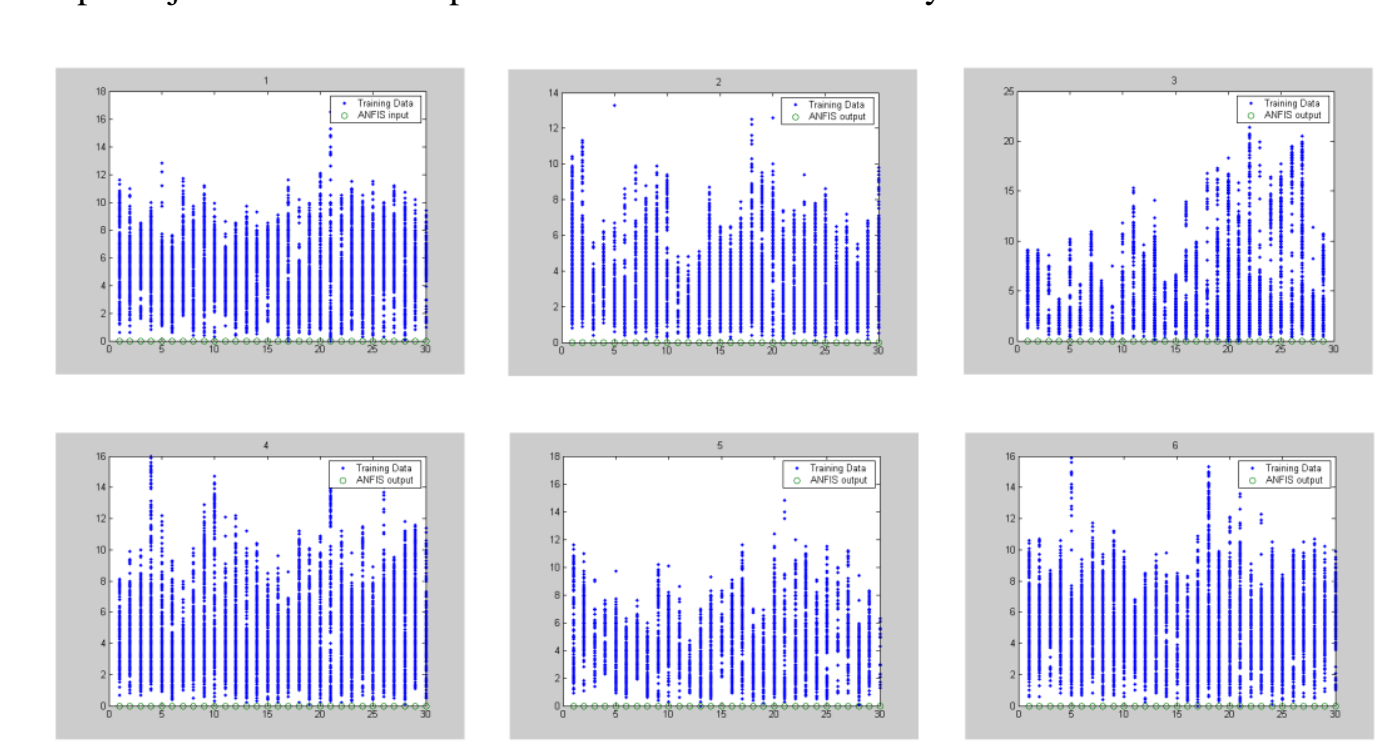

Figure 16. ANFIS Output before Training of Training Data 

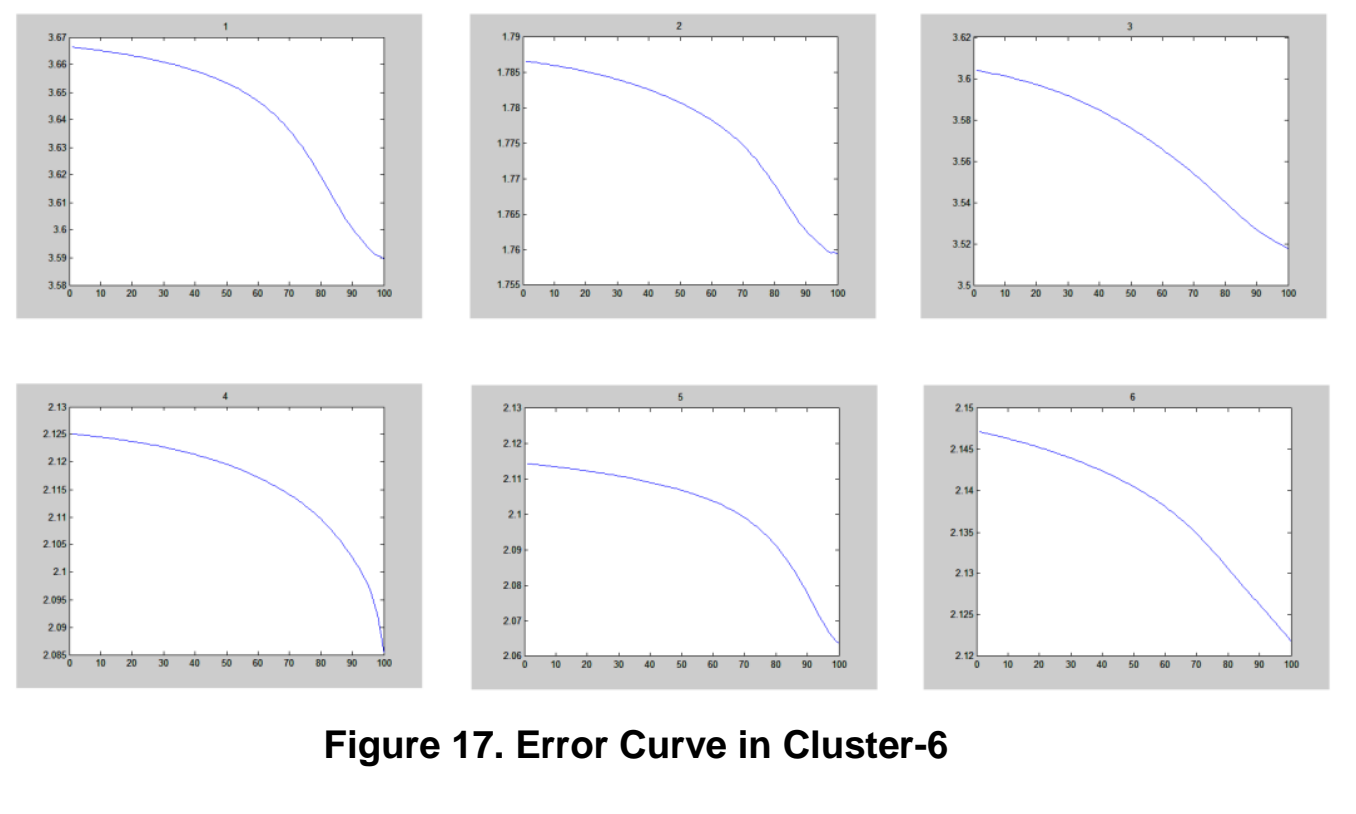

Figure 17. Error Curve in Cluste -6

The chart above shows assembly of error curyes of ANFIS by thaining. The next chart shows ANFIS output by lunar date in 6 clusters.

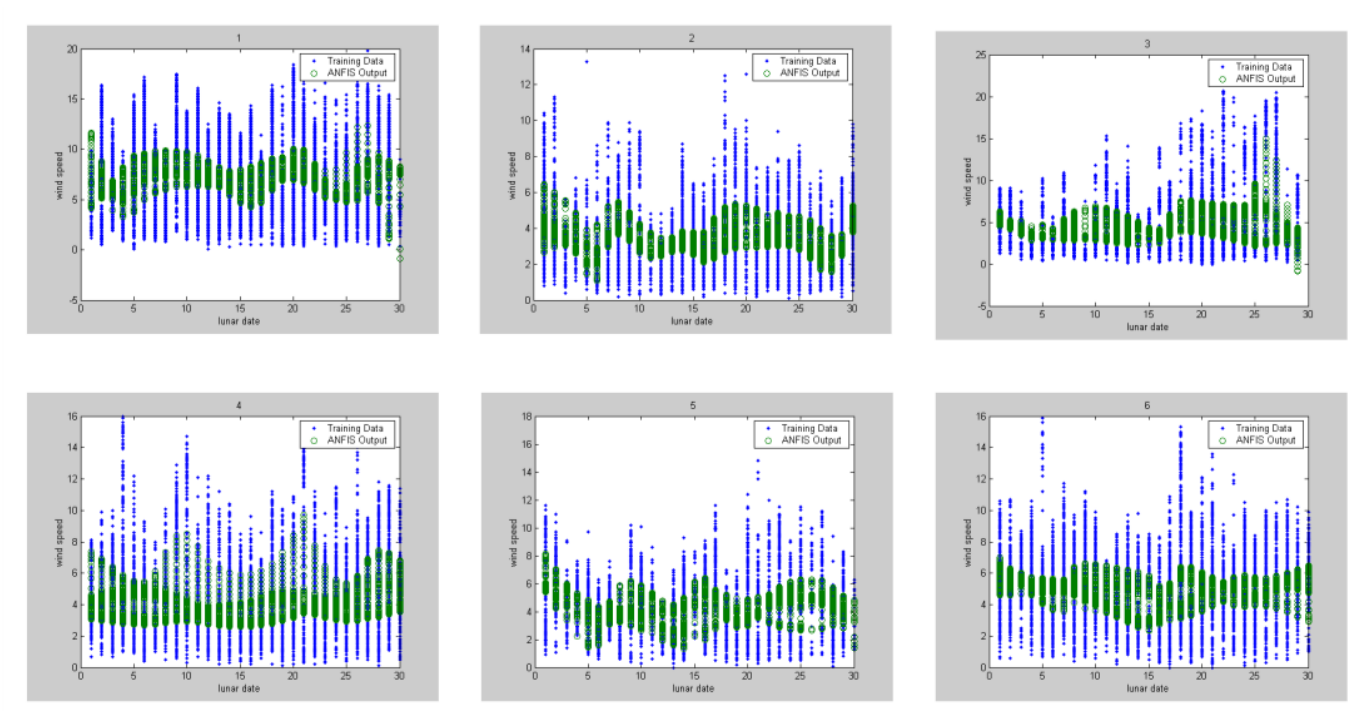

Figure 18. ANFIS Output by Lunar Date

The nartabove shows assembly of ANFIS output by lunar date. The next chart shows assembly of ANFIS output by wind direction. 

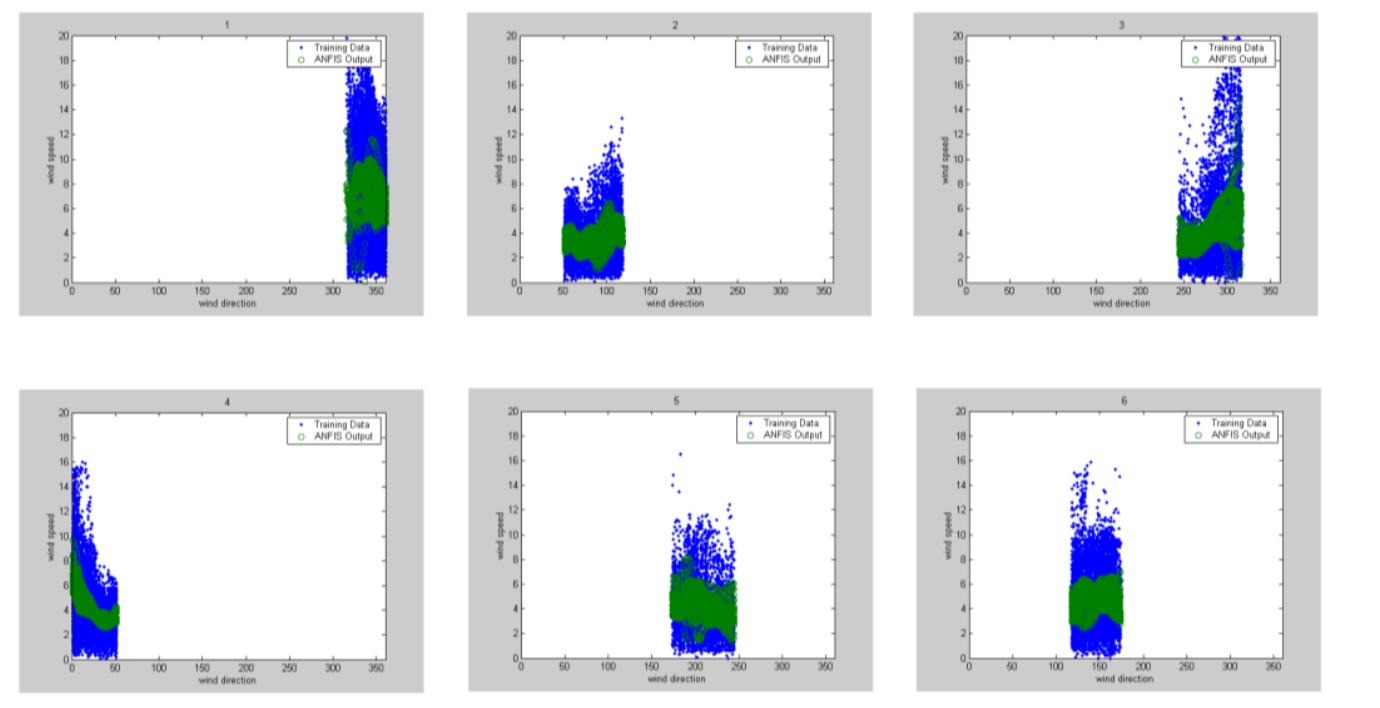

Figure 19. ANFIS Output by Wind Direction

\section{Conclusion}

Wind power energy is receiving attention in recent years. The properties of wind are very hard to predict because of its nonlinear haracteristics. ANFIS is an attractive tool for prediction of nonlinear system. ANFIS consists of adaptive Neural network and Fuzzy inference system of Takagi-Sugeno modê

The data were measured for one yeai from December 2012 to November 2013 by 10 minute interval. One year and 10 minute interyal makes 52,560 samples of data but use 48,240 samples instead for stable operation.

For prediction of wind speed the covariance was examined. As a result, the input domain consists of lunar date and wind cirection. This input domain is big range of wind direction and lunar date so the whole range is partitioned by clusters.

For experiments, two type are chosen. one is 4 clusters and the other is 6 clusters. . The error of cluster- 6 is $75 \%$ lower than cluster- 4 . This means that the prediction of cluster- 6 is more accurate than cluster-4.

With four gaussian bell membership functions, ANFIS is trained over 200 epochs by clustered data. After training, ANFIS could predict the wind speed by lunar date and wind direction. Even if heayy nonlinear system can be predicted by ANFIS and FCM clustering.

\section{Acknowledginents}

This paper is a revised and expanded version of a paper entitled "Efficient Fuzzy Switch of Hybrid Wind Energy System" presented at "The 5th International Conference on Irformation Science and Industrial Applications, Harbin, August 19-20, 2016."

\section{References}

[1] T.-P. Hong and C.-Y. Lee, "Induction of fuzzy rules and membership functions from training examples", fuzzy set and Systems, vol. 84, iss. 1, (1996), pp.33-47.

[2] W. Pedrycz, "Conditional Fuzzy C-Means", Pattern Recognition Letters, vol. 17, iss. 6, (1996), pp. 625631.

[3] J.-S. R. Jang, "Input Selection for ANFIS Learning", Proceeding of the 5th IEEE International Conference of Fuzzy Systems, vol.2, (1996), pp.1493-1499.

[4] J.-S. Roger Jang, “Adaptive-Network-Based Fuzzy Inference System”, Systems, Man and Cybernetics, IEEE Transactions on, vol. 23, May-June (1993), pp. 665-685. 
[5] K. Mehdizadegan and K. Abbaszadeh, "Output power smoothing of PMSG-based wind energy conversion system equipped with matrix converter", 7th Power Electronics and Drive Systems Technologies Conference (PEDSTC), (2016), pp. 373 - 377.

[6] B. Taraghi and V. R. Jalali, "Fuzzy c-mean (FCM) clustering and Genetic Algorithm capability in predicting saturated hydraulic conductivity", International Congress on Technology, Communication and Knowledge (ICTCK), vol. 2014, (2014), pp. 1-6.

[7] A. Kumar and D. GiriBabu, "Performance improvement of DFIG fed Wind Energy Conversion system using ANFIS controller", 2nd International Conference on Advances in lectrical, Electronics, Information, Communication and Bio-Informatics (AEEICB), (2016), pp. 202 - 206.

[8] Y. H. Ko, "Efficient Fuzzy Switch of Hybrid Wind Energy System", The 5th International Conference on Information Science and Industrial Applications, (2016).

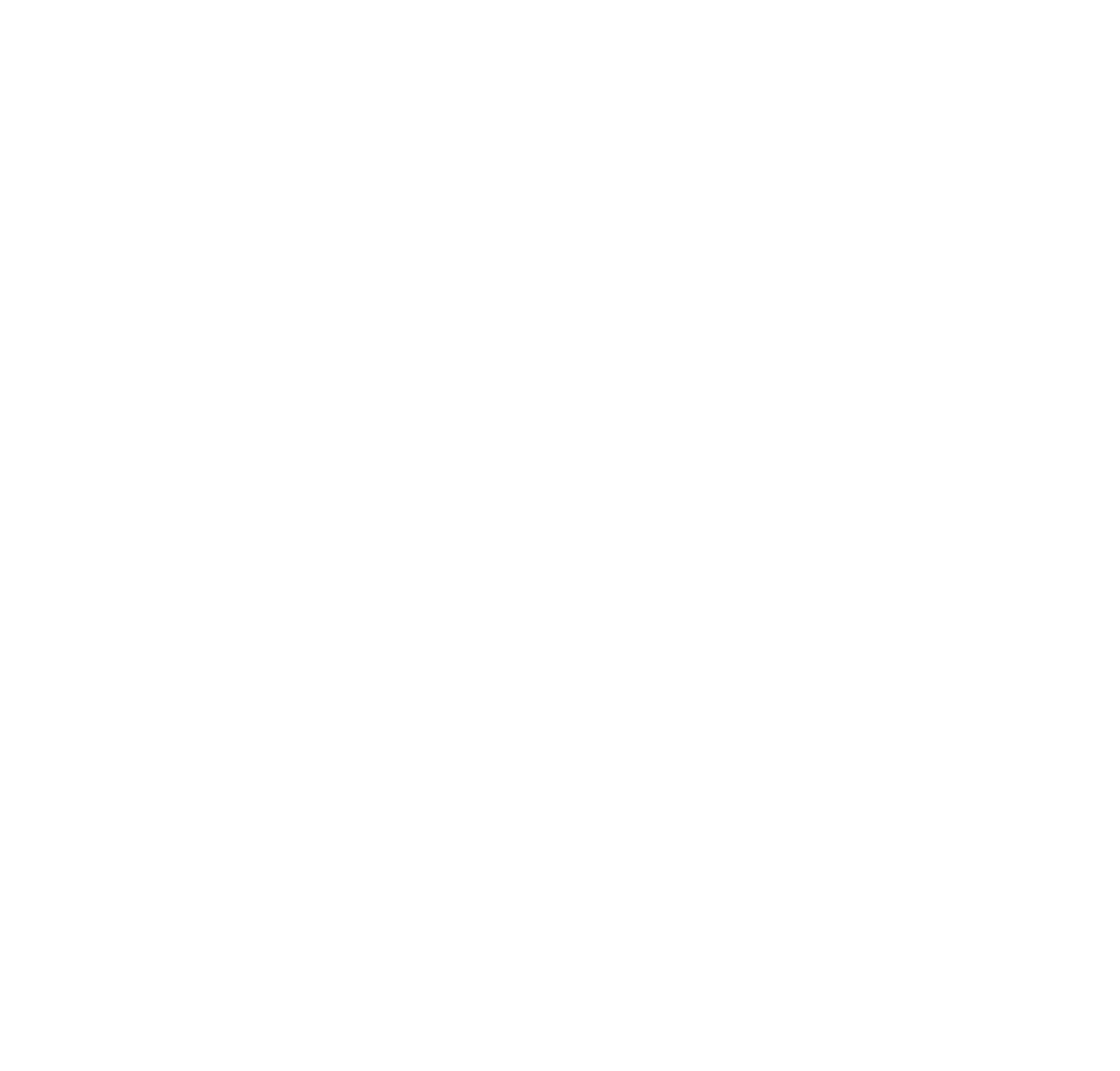


International Journal of Hybrid Information Technology

Vol. 9, No.10 (2016)

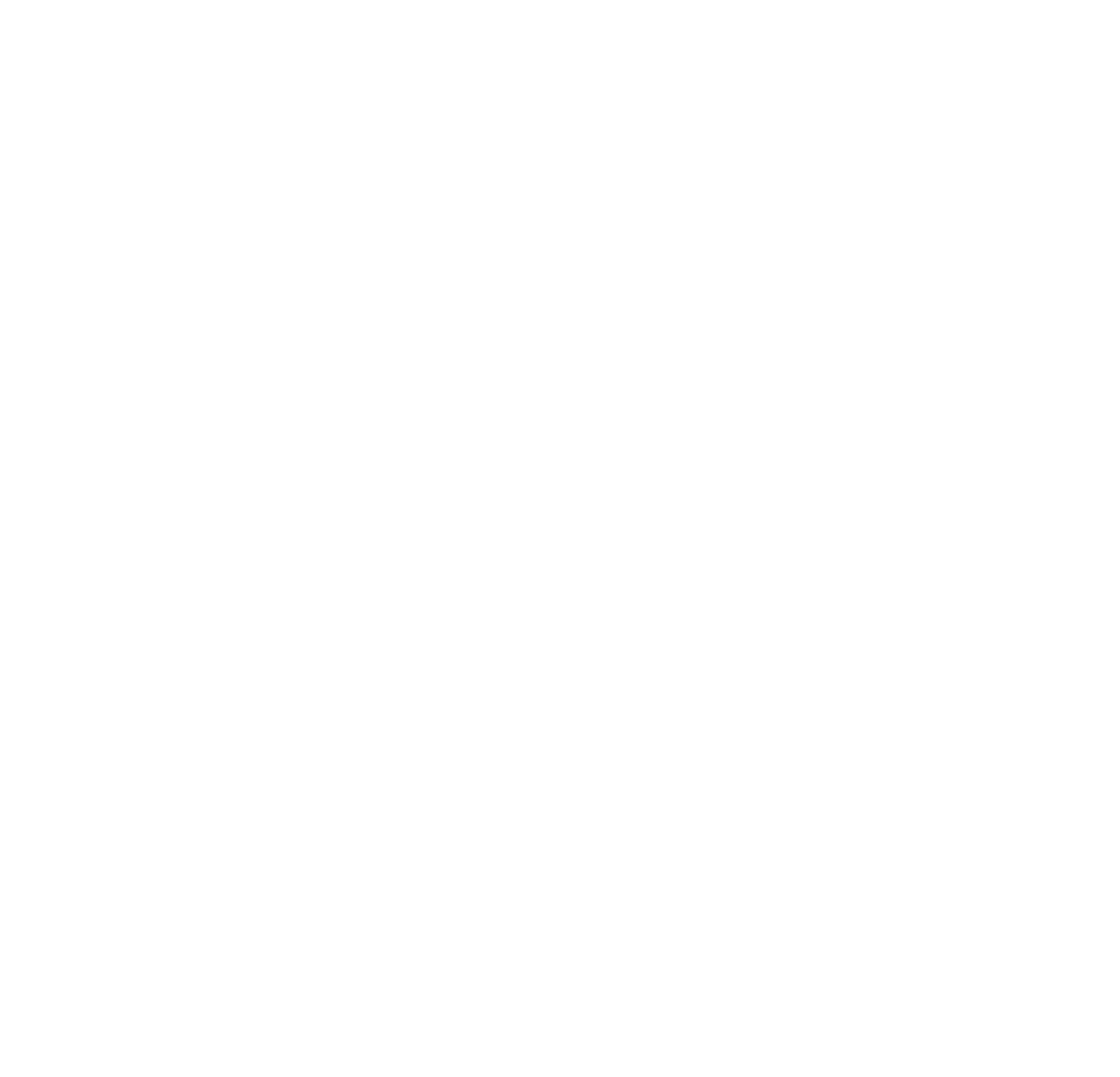

